\title{
Pulmonary Cryptococcosis: comparison of Cryptococcal antigen detection and radiography in Immunocompetent and Immunocompromised patients
}

\author{
Jingqi Min ${ }^{1}$, Kunlun Huang ${ }^{1}$, Chanmei Shi ${ }^{1}$, Laifu Li ${ }^{1}$, Fuye Li ${ }^{1}$, Tao Zhu ${ }^{2}$ and Huojin Deng ${ }^{1 *}$
}

\begin{abstract}
Background: We compared the cryptococcal antigen detection and imaging findings between immunocompetent and immunocompromised patients in whom pulmonary cryptococcosis had been diagnosed. The aim of our study was to determine whether the patient's immune status and radiography affect the detection of cryptococcal antigen.

Methods: According to whether they took immunosuppressive drugs or not, seventy and eight adult patients with pulmonary cryptococcosis were divided into two groups: the immunocompetent group and the immunocompromised group. According to the detection of $\mathrm{CrAg}$, each group was divided into the $\mathrm{CrAg}+$ group and the CrAg- group. Then, clinical records, laboratory examinations and computed tomography findings were collected and analyzed.

Results: No difference was found in baseline characteristics, clinical symptoms, and laboratory investigations. By comparing CrAg detection in these two groups, it was found that the number of $\mathrm{CrAg}+$ cases in the immunocompetent group was more than that in the immunocompromised group. And in the immunocompetent group, diffuse lesions were more common in $\mathrm{CrAg}+$ group and limited lesions were more frequently observed in CrAg-group.

Conclusions: The patient's immune status and radiography would affect the detection of cryptococcal antigen. And serum CrAg could be a useful tool for the diagnosis of pulmonary cryptococcosis in immunocompetent patients with extensive lung involvement.
\end{abstract}

Keywords: Cryptococcosis, Immune, Serum cryptococcal antigen (CrAg)

\section{Background}

Pulmonary cryptococcosis caused by Cryptococcus neoformans C. Cryptococcus complexes is very common in immunocompromised individuals, and it has become an emerging disease in immunocompetent ones [1-3]. Some reports have shown that pulmonary cryptococcosis occurs more frequently in immunocompetent patients than in immunocompromised ones $[4,5]$. Compared with the current high incidence, the diagnosis of

\footnotetext{
* Correspondence: denghj51889@126.com

${ }^{1}$ Department of Pulmonary and Critical Care Medicine, Zhujiang Hospital,

Southern Medical University, Guangzhou 510280, China

Full list of author information is available at the end of the article
}

pulmonary cryptococcosis is still difficult because the clinical manifestations and imaging of pulmonary cryptococcosis have no obvious characteristics compared with other pulmonary diseases [6-8]. At present, diagnostic therapy and lung biopsy are mostly used to help diagnosis in China. But both methods have their drawbacks. Diagnostic using antifungal drugs have a long diagnosis cycle and side effects, and lung biopsy also has some indications, and it is invasive, difficult and complex to operate. Therefore, it is necessary to find a noninvasive and reliable method with few side effects. Some research [9-12] have shown that serum $\mathrm{CrAg}$ is a useful diagnostic methods. However, Serum $\mathrm{CrAg}$ detection

(c) The Author(s). 2020 Open Access This article is distributed under the terms of the Creative Commons Attribution 4.0 International License (http://creativecommons.org/licenses/by/4.0/), which permits unrestricted use, distribution, and reproduction in any medium, provided you give appropriate credit to the original author(s) and the source, provide a link to the Creative Commons license, and indicate if changes were made. The Creative Commons Public Domain Dedication waiver (http://creativecommons.org/publicdomain/zero/1.0/) applies to the data made available in this article, unless otherwise stated. 


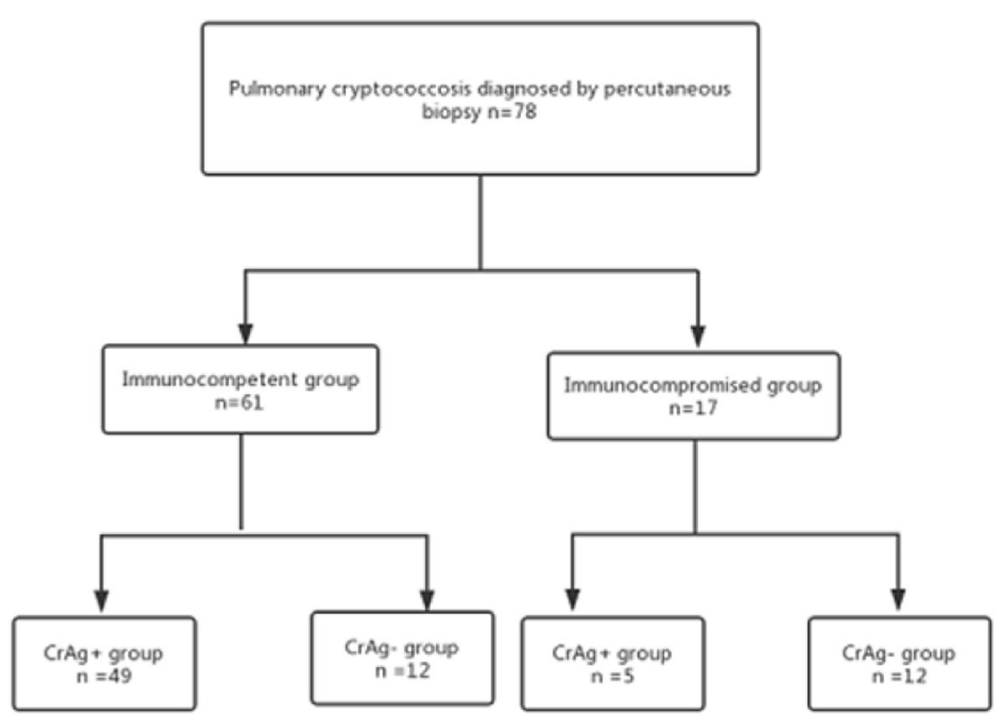

Fig. 1 Flow diagram of the study patient selection

negative is common among patients with Pulmonary cryptococcosis. Recent study [13] has shown that serum $\mathrm{CrAg}$ is a useful diagnostic tool for pulmonary cryptococcosis in patients with extensive lung invasion. Based on that, we speculate that the radiological manifestations may affect the detection of serum CrAg. In addition, in a large number of clinical observations, we found that the immune status will also have an impact on their detection. (because the incidence of AIDS in China is relatively low, so it will not be discussed here.) Considering the above information, we want to figure out whether the pulmonary radiography and immune status could affect the $\mathrm{CrAg}$ detection.

\section{Methods}

\section{Study subjects}

We retrospectively examined the hospitalized patients with pulmonary cryptococcosis between January 2012 and March 2019 in Zhujiang Hospital of Southern Medical University (Guangdong, China), Hospital of Southern Medical University (Guangdong, China) and Guangzhou People's Hospital (Guangdong, China). All patients' diagnoses were confirmed by percutaneous transthoracic needle biopsy (PTNB) or postoperative biopsy, and diagnosed by histopathological observations. Then, the data and information were collected: (1) demographic features and past medical history; (2) clinical features and symptoms; (3) laboratory tests, including white blood cell (WBC) counts, neutrophils counts, lymphocytes counts, concentrations of hemoglobin $(\mathrm{Hb})$, platelet counts (PLT); (4) serum CrAg was detected by lateral flow assay (LFA) (IMMY, Norman, OK, USA); (5) chest radiological findings [Fig. 1]. Seventy-eight patients with pulmonary cryptococcosis were divided into two groups: the immunocompetent group and the immunocompromised group, according to whether they took immunosuppressive drugs or not. According to the detection of $\mathrm{CrAg}$, each group was divided into the $\mathrm{CrAg}+$ group and the CrAg- group. Then, according to Tao Zhu's research [13], we define diffuse lesions as multiple lobes of the lung, multiple lesions of a single lobe, or lesions of a single lobe larger than $3 \mathrm{~cm}$ in diameter. Limited lesions are defined as lesions with a diameter of less than $3 \mathrm{~cm}$ in a single lobe. This study was approved by research Southern Pearl River Hospital Ethics Committee Medical University (No. 2016 HXNK 007), and all patients signed informed consents.

Table 1 Medical history of patients with pulmonary cryptococcosis

\begin{tabular}{llll}
\hline Characteristics & $\begin{array}{l}\text { Immunocompetent } \\
\text { group }\end{array}$ & $\begin{array}{l}\text { Immunocompromised } \\
\text { group }\end{array}$ & $\mathrm{P}$ \\
\hline $\mathrm{n}$ & 61 & 17 & \\
Male(\%) & $38(62.0)$ & $11(64.0)$ & $0.86^{c}$ \\
Age & 44.82 & 43.06 & $0.65^{\mathrm{t}}$ \\
Asymptomatic (\%) & $17(27.87)$ & $2(11.76)$ & $0.29^{c}$ \\
Cough(\%) & $44(72.13)$ & $15(88.24)$ & $0.29^{c}$ \\
expectoration (\%) & $34(55.74)$ & $10(58.82)$ & $0.82^{c}$ \\
Chest pain (\%) & $14(22.95)$ & $4(23.53)$ & $1.00^{c}$ \\
Fever (\%) & $8(13.11)$ & $3(17.65)$ & $0.94^{c}$ \\
$\begin{array}{l}\text { Underlying } \\
\text { diseases (\%) }\end{array}$ & $2(0.03)$ & $17(100)$ & \\
Hypertension & 2 & & \\
Kidney & 0 & 15 & \\
transplantation & & 2 & \\
Leukemia & 0 & & \\
\hline Chi-square test; & & & \\
\hline
\end{tabular}

${ }^{\mathrm{c}}$ Chi-square test; ${ }^{\mathrm{t}} \mathrm{t}$-test 
Table 2 Laboratory investigations of patients with pulmonary cryptococcosis

\begin{tabular}{llll}
\hline Characteristics & Immunocompetent group & Immunocompromised group & $P$ \\
\hline WBC $\left(10^{9} / \mathrm{L}\right)$ & $7.27 \pm 1.96$ & $7.93 \pm 2.57$ & $0.26^{t}$ \\
Neutrophils & $4.87 \pm 1.92$ & $5.83 \pm 1.94$ & $0.07^{t}$ \\
Lymphocytes & $1.89 \pm 0.57$ & $1.75 \pm 0.38$ & $0.66^{t}$ \\
Hb(g/L) & $131.00 \pm 17.87$ & $121.70 \pm 23.47$ & $0.08^{t}$ \\
PLT $\left(10^{9} / \mathrm{L}\right)$ & $291.98 \pm 107.67$ & $258.41 \pm 116.67$ & $0.26^{t}$ \\
\hline
\end{tabular}

${ }^{c}$ Chi-square test; ${ }^{\mathrm{t}} \mathrm{t}$-test. WBC White blood cell; $\mathrm{Hb}$ Hemoglobin

\section{Statistical analysis}

Statistical analyses were performed with SPSS software, version 20.0. Continuous data are presented as the mean \pm standard deviation or range. Chi-square test was used to analyze categorical variable. The independent t-test was obtained to analyze continuous variable. $P<0.01$ was considered statistically significant.

\section{Results}

\section{Demographics and clinical data}

Patient demographic and clinical information is summarized in Table 1. Our patients ranged in age from 15 to 81 years (mean age, 44.44 years). Forty-nine patients were male and 29 were female. Sixty-one patients had no immunodeficiency disorders, and 17 patients had received immunosuppressive therapy for a disease, 15 renal transplant patients received immunosuppressive therapy with cyclosporine, corticosteroids and mycophenolate. Two patients with acute leukemia received VP regimen (vincristine + prednisone) as chemotherapy regimen. Cough was the most common presenting symptom, occurring in 44 immunocompetent patients (72.13\%) and 15 in immunocompromised patients (88.24\%), followed by expectoration $(55.74 \%$ vs $58.82 \%)$, chest pain $(22.95 \%$ vs $23.53 \%)$, and fever $(13.11 \%$ vs $17.65 \%)$. Nineteen people were asymptomatic, 17 of whom had no immunodeficiency disease. There was no significant difference in the levels of WBC, neutrophils, lymphocytes, $\mathrm{Hb}$ and PLT between two groups (Table 2).

\section{Serum cryptococcal antigen and immune status}

By comparing the results of cryptococcal antigen test in two groups, we found that the number of $\mathrm{CrAg}+$ cases in the immunocompetent group was more than that in the immunocompromised group (49 vs 5 ), which was a

Table 3 Comparison of Cryptococcal Antigen Detection in the Immunocompetent and Immunocompromised group

\begin{tabular}{llll}
\hline $\begin{array}{l}\text { CrAg } \\
\text { expression }\end{array}$ & $\begin{array}{l}\text { Immunocompetent } \\
\text { group }\end{array}$ & $\begin{array}{l}\text { Immunocompromised } \\
\text { group }\end{array}$ & $P$ \\
\hline CrAg+ & 49 & 5 & $0.0001^{a}$ \\
CrAg- & 12 & 12 & \\
\hline
\end{tabular}

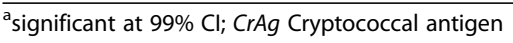

significant statistical difference between the two groups $(P<0.01)$. (Table 3$)$.

\section{Chest radiology}

Table 4 showed that diffuse extent lesion was more common in $\mathrm{CrAg}+$ group and limited extent lesion was more frequently observed in CrAg- group among the immunocompetent group $(47$ vs 7$)(\mathrm{P}<0.01)$. On the contrary, in the immunocompromised group, more diffuse lesions were found in the CrAg-group than in the CrAg+ group $(10$ vs 4$)(P>0.01)$, as shown in Table 5 . Chest radiology and biopsy results in patients with pulmonary cryptococcosis were shown in Fig. 2.

\section{Treatment}

There were 12 patients who received surgical resection, 5 patients who received surgery combined with antifungal drugs, 58 patients who received Antifungal monotherapy (56 cases were treated with fluconazole, 2 cases were treated with amphotericin), and 3 patients who were confirmed by biopsy were discharged from the hospital without treatment. (Table 6).

\section{Prognosis}

The follow-up data of 23 patients were complete. In the immunocompetent group, all lesions were removed by operation in four patients and no recurrence was found in follow-up for several months. And 15 patients were treated with fluconazole alone. After treatment, it was found that all lesions were absorbed. In the immunocompromised group, 2 patients were treated with surgery combined with fluconazole, 1 patient was treated with fluconazole initially, and then was treated with amphotericin and sequential voriconazole. Lesions were cleared in all 3 patients. And all of them were limited extent lesion.

Table 4 Comparison of Cryptococcal Antigen Detection and Radiography in the Immunocompetent group

\begin{tabular}{llll}
\hline Characteristics & $\mathrm{CrAg}+$ & $\mathrm{CrAg}^{-}$ & $\mathrm{P}$ \\
\hline Diffuse extent lesion & 47 & 7 & $0.002^{\mathrm{a}}$ \\
Limited extent lesion & 2 & 5 & \\
\hline
\end{tabular}

asignificant at 99\% Cl; $\mathrm{CrAg}$ Cryptococcal antigen 
Table 5 Comparison of Cryptococcal Antigen Detection and Radiography in the Immunocompromised group

\begin{tabular}{llll}
\hline Characteristics & $\mathrm{CrAg}+$ & $\mathrm{CrAg}^{-}$ & $\mathrm{P}$ \\
\hline Diffuse extent lesion & 4 & 10 & $1^{\mathrm{a}}$ \\
Limited extent lesion & 1 & 2 & \\
\hline
\end{tabular}

${ }^{a}$ significant at $99 \% \mathrm{Cl} ; \mathrm{CrAg}$ Cryptococcal antigen

\section{Discussion}

In this study, a retrospective research of 78 patients with pulmonary cryptococcosis was conducted to investigate whether the patient's immune status and radiography affect the detection of cryptococcal antigen. Firstly, according to the patient's immune status, we divided these pulmonary cryptococcosis patients diagnosed by lung biopsy into the immunocompetent group and the immunocompromised group. We found the number of $\mathrm{CrAg}+$ cases in the immunocompetent group was more than that in the immunocompromised group. This may indicate that the positive detection of serum cryptococcal antigen in immunocompetent individuals is more likely to represent the infection of pulmonary cryptococcosis. Moreover, in the immunocompetent group, diffuse lesions were more common in $\mathrm{CrAg}+$ group and limited lesions were more frequently observed in CrAg-group. It suggests that the possibility of pulmonary cryptococcal infection is high, when immunocompetent patients with diffuse lung lesions have a positive serum cryptococcal antigen test. It has been reported that the detection of serum cryptococcal antigen is often negative in patients who have isolated pulmonary, and the presence of a positive serum cryptococcal antigen means the high possibility of deep tissue infiltration and disseminated diseases, [14-16]. But the result in the immunocompromised group was contrary $(p>0.01)$, which may be related to the small sample size. The radiological findings of patients with pulmonary cryptococcosis are non-specific, and depend on the immune status of patients. In immunocompetent patients, solitary or multiple pulmonary nodules are common, while in immunocompromised patients, cavities often appear $[15,17]$. Our findings in immunocompetent individuals have expanded the value of serum $\mathrm{CrAg}$ in the diagnosis of diffuse lesion in immunocompetent patients, supporting the results of previous studies that the most common CT findings of pulmonary cryptococcosis was multiple pulmonary nodules/masses of different diameters [18-21].

Similar to previous reports, our study also found that the most common symptoms of pulmonary cryptococcosis patients included cough and sputum, [5, 22-24] with no significant specificity(Table 1). Our laboratory examinations, including leucocyte, neutrophil, lymphocyte, $\mathrm{Hb}$ and PLT levels, showed no significant difference between immunocompetent and immunodeficient groups (Table 2). This may confirm that cryptococcosis can inhibit the aggregation of pulmonary neutrophils and the production of inflammatory cytokines in immunocompetent host, thus affecting the immune function of healthy subjects $[23,25]$.

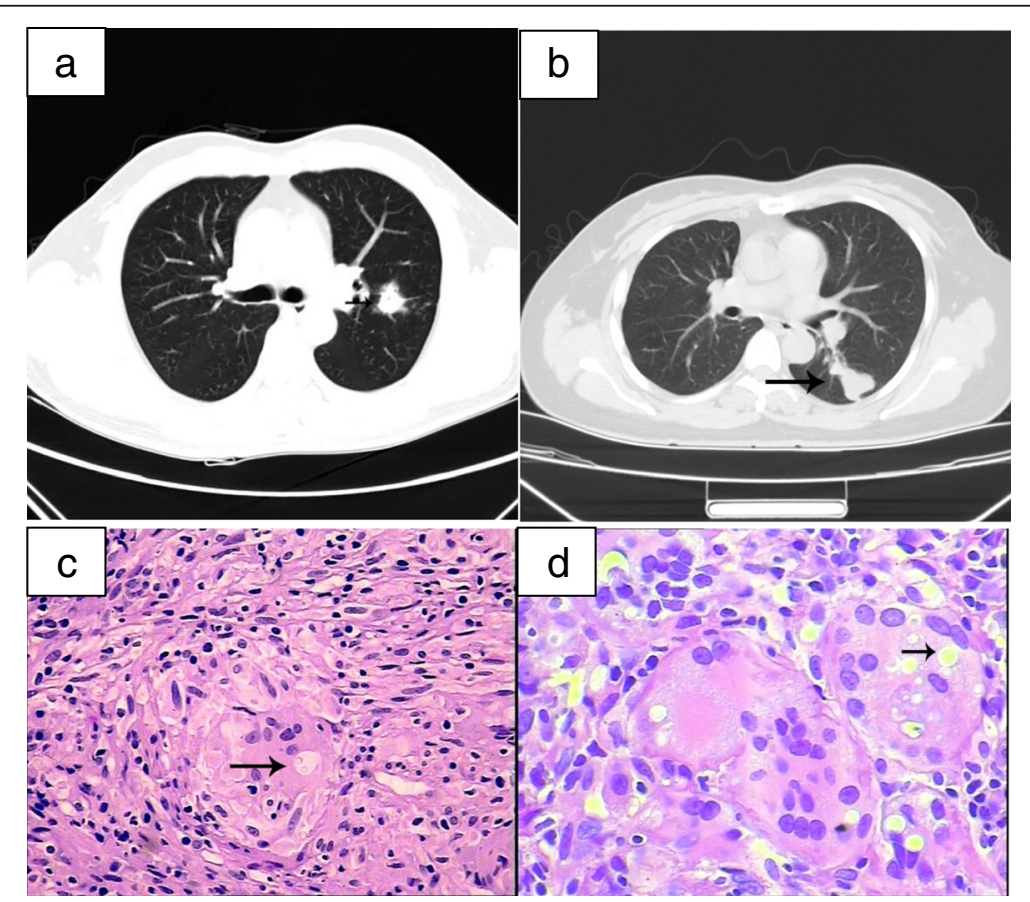

Fig. 2 The chest radiological findings and biopsy results in patients with pulmonary cryptococcosis. (a) lesion (the diameter $<3 \mathrm{~cm}$ ) in a single lobe (limited extent lesion). (b) lesions in multiple lobes (diffuse extent); Lesion (black arrows). Biopsy results (c-d), Cryptococcus sp. yeasts (black arrows) 
Table 6 Comparison of treatment in the Immunocompetent and Immunocompromised group

\begin{tabular}{lllllll}
\hline Characteristics & $\mathrm{N}$ & Operation & $\begin{array}{l}\text { Fluconazole } \\
\text { monotherapy }\end{array}$ & $\begin{array}{l}\text { Operation combined } \\
\text { with fluconazole }\end{array}$ & $\begin{array}{l}\text { Amphotericin } \\
\text { monotherapy }\end{array}$ & $\begin{array}{l}\text { Other } \\
\text { Immunocompetent group }\end{array}$ \\
Immunocompromised group & 61 & 10 & 3 & 48 & 0 & 0 \\
\hline
\end{tabular}

In conclusion, patient's immune status and CT manifestations would affect the detection of serum cryptococcal antigen. Serum CrAg could become a useful tool for the diagnosis of pulmonary cryptococcosis in immunocompetent patients with extensive lung involvement.

\section{Future work}

Of course, there are some limitations. First of all, this is a retrospective study. We collected a relatively small number of cases, so we will expand the sample size and a series of cohort studies will be conducted next. And as pulmonary physicians, our research is limited to pulmonary cryptococcosis. In the future, we will strengthen cooperation with other departments and hospitals to deepen our understanding of cryptococcal and serum cryptococcal antigen detection. Finally, because of the incomplete data, we have not classified the pathogenic bacteria of cryptococcosis. From now on, we will continue to study whether the infection of specific Cryptococcus is related to the immune status of patients, CT findings and cryptococcal antigen detection.

\section{Abbreviations}

AIDS: Acquired immune deficiency syndrome; CrAg: Cryptococcal antigen; CrAg-: Cryptococcal antigen negative; $\mathrm{CrAg}+$ : Cryptococcal antigen positive; CT: Computed tomography; Hb: Hemoglobin; HIV: Human immunodeficiency virus; PLT: Platelet counts; WBC: White blood cell

\section{Acknowledgements}

The authors would like to thank the study participants and Xueqin Liu and Jie Xu for her help during the data collection phase.

\section{Authors' contributions}

All of the authors had access to the full data set (including the statistical Reports and tables) and take responsibility for the integrity of the data and the accuracy of the data analysis. JQM and HJD conceived the study. KLH, CMS, LFL, FYL and TZ collected the data and designed the analysis. JQM interpreted the data. JQM wrote the first draft of the paper. $\mathrm{KLH}$, FYL helped improve the English language of articles. HJD review and approved the final report. All authors read and approved the final manuscript.

\section{Funding}

This study was supported by a grant from the Guangdong Science and Technology Department (2014A020212627, 2016A020215099).

\section{Availability of data and materials}

The data that support the findings of this study are available from the corresponding author upon reasonable request.

\section{Ethics approval and consent to participate}

This study was approved by research Southern Pearl River Hospital Ethics Committee Medical University (No. 2016 HXNK 007), and all patients signed informed consents.

\section{Consent for publication}

Not applicable.

\section{Competing interests}

The authors declare that they have no competing interests.

\section{Author details}

'Department of Pulmonary and Critical Care Medicine, Zhujiang Hospital, Southern Medical University, Guangzhou 510280, China. ${ }^{2}$ Department of Pulmonary and Critical Care Medicine, Second Affiliated Hospital, Chongqing Medical University, Chongqing, China.

Received: 28 July 2019 Accepted: 23 January 2020

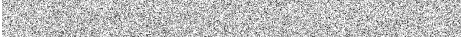

\section{References}

1. Fisher JF, Valencia-Rey PA, Davis WB. Pulmonary Cryptococcosis in the Immunocompetent patient-many questions, Some Answers. Open Forum Infect Di. 2016;3(3):w167.

2. Setianingrum F, Rautemaa-Richardson R, Denning DW. Pulmonary cryptococcosis: a review of pathobiology and clinical aspects. Med Mycol, 2019;57(2):133-50.

3. Zhang Y, Li N, Zhang Y, Li H, Chen X, Wang S, Zhang X, Zhang R, Xu J, Shi J, et al. Clinical analysis of 76 patients pathologically diagnosed with pulmonary cryptococcosis. Eur Respir J. 2012;40(5):1191-200.

4. Liu K, Ding H, Xu B, You R, Xing Z, Chen J, Lin Q, Qu J. Clinical analysis of non-AIDS patients pathologically diagnosed with pulmonary cryptococcosis. J Thorac Dis. 2016;8(10):2813-21.

5. Chang W, Tzao C, Hsu H, Lee S, Huang K, Tung H, Chen C. Pulmonary Cryptococcosis: comparison of clinical and radiographic characteristics in Immunocompetent and Immunocompromised patients. Chest. 2006;129(2): $333-40$.

6. Ye F, Xie J, Zeng $\mathrm{Q}$, Chen $\mathrm{G}$, Zhong $\mathrm{S}$, Zhong $\mathrm{N}$. Retrospective analysis of $\mathbf{7 6}$ Immunocompetent patients with primary pulmonary Cryptococcosis. Lung. 2012;190(3):339-46.

7. Gao L, Jiao A, Wu X, Zhao S, Ma Y, Liu G, Yin J, Xu B, Shen K. Clinical characteristics of disseminated cryptococcosis in previously healthy children in China. BMC Infect Dis. 2017;17(1):310-59.

8. Deng H, Zhang J, Li J, Wang D, Pan L, Xue X. Clinical features and radiological characteristics of pulmonary cryptococcosis. J Int Med Res. 2018:46(7):2687-95.

9. Gazzoni AF, Severo CB, Salles EF, Severo LC. Histopathology, serology and cultures in the diagnosis of cryptococcosis. Rev Inst Med Trop Sao Paulo. 2009:51(5):255-9.

10. De Pauw B, Walsh TJ, Donnelly JP, Stevens DA, Edwards JE, Calandra T, Pappas PG, Maertens J, Lortholary O, Kauffman CA, et al. Revised definitions of invasive fungal disease from the European Organization for Research and Treatment of cancer/invasive fungal infections cooperative group and the National Institute of Allergy and Infectious Diseases mycoses study group (EORTC/MSG) consensus group. Clin Infect Dis. 2008;46(12):1813-21.

11. Lin T, Yeh K, Lin J, Wang N, Peng M, Chang F. Cryptococcal disease in patients with or without human immunodeficiency virus: clinical presentation and monitoring of serum cryptococcal antigen titers. J Microbiol Immunol Infect. 2009;42(3):220.

12. Pappas PG, Perfect JR, Cloud GA, Larsen RA, Pankey GA, Lancaster DJ, Henderson H, Kauffman CA, Haas DW, Saccente M, et al. Cryptococcosis in human immunodeficiency virus-negative patients in the era of effective azole therapy. Clin Infect Dis. 2001;33(5):690-9.

13. Zhu T, Luo WT, Chen GH, Tu YS, Tang S, Deng HJ, Xu W, Zhang W, Qi D, Wang DX, et al. Extent of lung involvement and serum Cryptococcal antigen test in non-human immunodeficiency virus adult patients with pulmonary Cryptococcosis. Chin Med J. 2018;131(18):2210-5. 
14. Singh N, Dromer F, Perfect JR, Lortholary O. Immunocompromised hosts: Cryptococcosis in solid organ transplant recipients: current state of the science. Clin Infect Dis. 2008:47(10):1321-7.

15. Smith JA, Kauffman CA. Pulmonary fungal infections. Respirology. 2012;17: 913-26.

16. Saag MS, Graybill RJ, Larsen RA, Pappas PG, Perfect JR, Powderly WG, Sobel JD, Dismukes WE. Practice Guidelines for the Management of Cryptococcal Disease. Clin Infect Dis. 2000;30:710-8.

17. Baddley JW, Perfect JR, Oster RA, Larsen RA, Pankey GA, Henderson H, Haas DW, Kauffman CA, Patel R, Zaas AK, et al. Pulmonary cryptococcosis in patients without HIV infection: factors associated with disseminated disease. Eur J Clin Microbiol. 2008;27(10):937-43.

18. Xie L, Chen Y, Liu S, Shi Y. Pulmonary cryptococcosis: comparison of CT findings in immunocompetent and immunocompromised patients. Acta Radiol. 2015;56(4):447-53.

19. Qu Y, Liu G, Ghimire P, Liao M, Shi H, Yang G, Xu L, Wang G. Primary pulmonary cryptococcosis: evaluation of $C T$ characteristics in 26 immunocompetent Chinese patients. Acta Radiol. 2012;53(6):668-74.

20. Fox DL, Müller NL. Pulmonary cryptococcosis in immunocompetent patients: CT findings in 12 patients. AJR. 2005;185(3):622.

21. Fox DL, Muller NL. Pulmonary cryptococcosis in immunocompetent patients: CT findings in 12 patients. AJR. 2005;185(3):622-6.

22. Xie X, Xu B, Yu C, Chen M, Yao D, Xu X, Cai X, Ding C, Wang L, Huang X. Clinical analysis of pulmonary cryptococcosis in non-HIV patients in South China. Int J Clin Exp Med. 2015;8(3):3114.

23. Wang J, Zeng Y, Luo W, Xie X, Li S. The role of Cryptococcus in the immune system of pulmonary Cryptococcosis patients. PLoS One. 2015;10(12): e144427.

24. Kohno S, Kakeya H, Izumikawa K, Miyazaki T, Yamamoto Y, Yanagihara K, Mitsutake K, Miyazaki Y, Maesaki S, Yasuoka A, et al. Clinical features of pulmonary cryptococcosis in non-HIV patients in Japan. J Infect Chemother. 2015;21(1):23-30.

25. Cheng P, Sham A, Kronstad JW. Cryptococcus gattii isolates from the British Columbia Cryptococcosis outbreak induce less protective inflammation in a murine model of infection than Cryptococcus neoformans. Infect Immun. 2009; $77(10): 4284-94$

\section{Publisher's Note}

Springer Nature remains neutral with regard to jurisdictional claims in published maps and institutional affiliations.

Ready to submit your research? Choose BMC and benefit from:

- fast, convenient online submission

- thorough peer review by experienced researchers in your field

- rapid publication on acceptance

- support for research data, including large and complex data types

- gold Open Access which fosters wider collaboration and increased citations

- maximum visibility for your research: over $100 \mathrm{M}$ website views per year

At $\mathrm{BMC}$, research is always in progress.

Learn more biomedcentral.com/submissions 